\title{
Clinical significance of serum amylase and glucose level in organophosphorus poisoning
}

\section{Manoj Koirala $^{1}$, Bishow Raj Baral ${ }^{1}$, Buddhisagar Lamichanne ${ }^{1}$}

${ }^{1}$ Department of Internal Medicine, Pokhara Academy of Health Sciences, Western Regional Hospital, Pokhara, Nepal.

\section{Correspondence:}

Dr. Manoj Koirala, MD,

Pokhara Academy of Health Sciences

Western Regional Hospital, Pokhara, Nepal

Email: koiralamanoj34@hotmail.com

Article received : $5^{\text {th }}$ May 2018

Article accepted : $7^{\text {th }}$ June 2019

\section{ABSTRACT}

Background: Organophosphorous(OP) poisoning is a common problem in country like Nepal where agriculture is the backbone of the economy. The primary mechanism of action is inhibition of acetylcholinesterase(ACHE). Organophosphorus poisoning is a possible cause of acute pancreatitis along with alternation of glucose metabolism.

Materials and Method: This was a hospital based crosssectional comparative study. The level of serum amylase and glucose were measured in thirty-eight OP poisoned patients at the time of admission, before discharge and were compared. Results: Amongst 38 patients, Majority had mild OP poisoning $27(71.1 \%)$ as per Peradeniya Organophosphorus Poisonin(POP) score whereas $9(23.7 \%)$ had moderate and $2(5.2 \%)$ had severe poisoning. The mean initial serum amylase level in patients with mild poisoning was $152 \pm 73.92(\mathrm{IU} / \mathrm{L})(\mathrm{p}=0.000)$, in moderate poisoning was $213.38 \pm 69.39(\mathrm{IU} / \mathrm{L})(\mathrm{p}=0.223)$ and in severe poisoning was $171.33 \pm 107.22$ (IU/L) $(\mathrm{p}=0.259)$. There was increase in serum amylase level in all patients with poisoning but level did not increase in proportion to increase with severity of POP score. The mean initial serum glucose level in mild poisoning was $132.48 \pm 37.73$ $(\mathrm{Mg} / \mathrm{dl})(\mathrm{p}=0.024)$, in moderate poisoning was $139 \pm 44.59$ $(\mathrm{Mg} / \mathrm{dl})(\mathrm{p}=0.033)$ and in severe poisoning was $174 \pm 23.38$ $(\mathrm{Mg} / \mathrm{dl})(\mathrm{p}=0.22)$. The serum glucose level increased as the severity of POP score increased. The serum amylase and glucose levels in recovering patients showed a tendency to decrease to their normal values. No patient had developed acute symptomatic pancreatitis. Conclusion: Serum amylase and glucose level were increased in all patients with OP poisoning but didn't correlate with the clinical severity. Routine measurement of serum amylase in patients of OP poisoning has little value in the absence of clinical acute pancreatitis.

Keywords: Acetylcholinesterase (ACHE), Organophosphorous (OP), Peradeniya Organophosphorus Poisoning (POP) 
Acute OP poisoning is one of the commonest poisoning in developing countries like Nepal where agriculture is the backbone of the country. The toxicity of OP poison and insufficient health facilities leads high mortality rate. The easy access of OP poison in vetenaries and sociocultural factors play an important role in choice of OP as a self-poison. The incidence of OP poison is higher among young economically active group.

World Health Organigaton estimates that one million of unintentional poisoning happened every year and an additional two million people are hospitalised for suicidal attempts with pesticides. ${ }^{1}$

Different hospital-based studies in Nepal also clearly demonstrated that OP compounds occupy the largest number of poisoning related morbidity and mortality. ${ }^{2}$ Four patients were expired amongst eighty patients who had been admitted in Bir hospital in the year 2003-2004. ${ }^{3}$ ACHE enzyme inhibition is the primary mechanism of actionof OP pesticides which degrades the neurotransmitter acetylcholine (ACHE) into choline and acetic acid. A deficiency of this enzyme causes accumulation of ACHE within synapses of nervous system and overstimulates the cholinergic receptors. OP also effects on autonomic, central nervous systems and nicotinic receptors of skeletal muscle. ${ }^{4}$

Both RBC and plasma cholinesterase levels can be used for diagnosis. RBC cholinesterase is a more useful marker of organophosphate poisoning. Plasma cholinesterase is easier to assay and is more readily available. Plasma cholinesterase level is the only option because measurement of RBC cholinesterase levels are not done in most laboratories of Nepal due to high cost. ${ }^{5}$ Case reports on clinical significance of hyperamylasemia and hyperglycemia in acute pancreatitis due to acute OP ingestion has been published but large-scale studies are lacking. The objective of this study was to find the clinical significance of serum amylase and glucose level through biochemical means.

\section{MATERIALS AND METHOD}

This study was a cross sectional hospital based study comparing two laboratory biomarkers and its clinical significance in OP poisoning. This study was conducted at National Academy of Medical Sciences, Bir Hospital,
Kathmandu. The study period was 10 months from June to march 2015.

Patients were enrolled from the emergency room. On admission, a detailed history was taken from the patient and/or caregiver. Confirmation of OP poisoning was done by seeing the packet/container of the poison consumed. Informed consent was taken from the caregivers. A thorough general physical and systemic examination was carried out and clinical severity was categorized according to Peradeniya Organophosphorus Poisoning (POP) scale. The levels of serum amylase and glucose were measured. Just before discharging the patients from hospital, the levels of serum Amylase and glucose was re-evaluated and the responses tabulated. Thirty eight adult patients of either sex with history of ingestion or exposure to OP poison presenting to emergency within 12 hours were included in study.

Patients with OP poisoning with known diabetes mellitus, history suggestive of chronic pancreatic diseases, history of intake of drugs eg: Oral contraceptive pills, Sulfadrugs, Valproat sodium, azathioprin, 6-Mercaptopurine, Tetracycline, Anti-retroviral medications, steroids and recent post endoscopic retrograde cholecystopancreatography status or undergone surgery patients were excluded from study. Sampling was nonprobability / purposive sampling and sampling population patients attending emergency room with OP poisoning. Patients were enrolled from the emergency department throughout the weekdays. Data entry was done in Microsoft exel software and statistical analysis done by using Statistical Package of Social Science (SPSS ) version 20. All categorical data were expressed in percent and absolute number. All numerical continuous data were expressed in mean \pm SD. All categorical data were analysed using Chi. square test. Paired t-test was used to compare serum initial and final amylase and glucose level. Results obtained from the study was discussed with reference to current world literature. For the purpose of this study a $95 \%$ confidence interval was accepted and a $\mathrm{P}$ value was considered

\section{RESULTS}

The majority, 17(44.74\%) OP poisoned patients were in the age group of $15-24$ years. $9(23.68 \%)$ patients were in the age group $25-34$ years, $5(13.16 \%)$ patients in the age group of $35-44$ yrs, $3(7.89 \%)$ patients in the age group 
$45-54$ years and $4(10.53 \%)$ in the age group more than 55years. Out of the 38 patients enrolled into the study 15(36.84\%) were males and 23(63.16\%) were females. The male : female ratio was approximately $1: 1.5$. All poisoning were suicidal(100\%).

The most common clinical feature at presentation was Tachypnoea(100\%) followed by Vomiting(92.1\%) then Salivation and lacrymation( $57.89 \%)$. Miosis, sweating and bradycardia occurred in $55.26 \%$ patients. Less frequent symptoms were Tachycardia $(2.6 \%)$ and hypertension $(2.6 \%)$. fasciculation is not seen in any patients. However most patients had overlap of the presenting symptoms.

As per POP score, 27(71.1\%) patients had mild OP poisoning, $9(23.7 \%)$ patients had moderate (POP score 4-7) OP poisoning and 2 (5.2\%) patients had severe (POP score 8-11) poisoning.

Normal serum amylase and glucose level taken as a reference range were $80-150 \mathrm{mg} / \mathrm{dl}$ and $70-140 \mathrm{mg} / \mathrm{dl}$ respectively.

Table 1. Comparision of the initial and final serum amylase levels

\begin{tabular}{|c|c|c|c|c|c|}
\hline \multirow{2}{*}{$\begin{array}{l}\text { POP } \\
\text { score }\end{array}$} & \multicolumn{2}{|c|}{ Initial amylase } & \multicolumn{2}{|c|}{ Final amylase } & \multirow{2}{*}{$\begin{array}{c}P \\
\text { value }\end{array}$} \\
\hline & Mean & \pm SD & Mean & \pm SD & \\
\hline $\operatorname{Mild}(0-3)$ & 152.67 & 73.92 & 104.89 & 15.51 & 0.000 \\
\hline Moderate(4-7) & 213.38 & 69.39 & 117.62 & 21.93 & 0.223 \\
\hline Severe(8-11) & 171.33 & 107.22 & 113.67 & 8.08 & 0.259 \\
\hline
\end{tabular}

The result of serum amylase showed that in patients with mild OP poisoning there was a reduction from the mean initial serum amylase level $(152.67 \pm 73.92 \mathrm{U})$ to the mean final serum amylase level $(104.89 \pm 15.51 \mathrm{U})$ $(\mathrm{p}<0.000)$. In patients with moderate OP poisoning there was a reduction from the mean initial serum amylase level $(213.38 \pm 69.39 \mathrm{U})$ to the mean final serum amylase level $(117.62 \pm 21.93 \mathrm{U})(\mathrm{p}<0.223)$ and in the group of patients with severe poisoning the reduction from the mean initial serum amylase level $(171.33 \pm 107.22 \mathrm{U})$ compared to the mean final serum amylase $(113.7 \pm 8.08$ $\mathrm{U})(\mathrm{p}=0.259)$.

The result of serum glucose showed that in patients with mild OP poisoning there was a reduction from the mean initial serum glucose level $(132.48 \pm 37.73 \mathrm{Mg} / \mathrm{dl})$ to the mean final serum glucose level $(96.03 \pm 22.62 \mathrm{Mg} / \mathrm{dl})$ $(\mathrm{p}<0.024)$. In patients with moderate OP poisoning there was a reduction from the mean initial serum glucose level $(139 \pm 44.59 \mathrm{Mg} / \mathrm{dl})$ to the mean final serum glucose level $(98.62 \pm 24.13 \mathrm{Mg} / \mathrm{dl})(\mathrm{p}<0.033)$. However in the group of patients with severe poisoning the reduction from the mean initial serum glucose level $(174 \pm 23.38$ $\mathrm{Mg} / \mathrm{dl}$ ) compared to the mean final serum glucose level $(108.67 \pm 1.53 \mathrm{Mg} / \mathrm{dl})(\mathrm{p}=0.259)$.

Table2. Comparision of the initial and final serum glucose levels

\begin{tabular}{|c|c|c|c|c|c|}
\hline \multirow{2}{*}{$\begin{array}{c}\text { POP } \\
\text { score }\end{array}$} & \multicolumn{2}{|c|}{ Initial amylase } & \multicolumn{2}{c|}{$\begin{array}{c}\text { Final } \\
\text { amylase }\end{array}$} & \multirow{2}{*}{$\begin{array}{c}\text { P } \\
\text { value }\end{array}$} \\
\cline { 2 - 5 } & Mean & \pm SD & Mean & \pm SD & \\
\hline Mild(0-3) & 132.48 & 37.73 & 96.03 & 22.62 & 0.024 \\
\hline Moderate(4-7) & 139 & 44.59 & 98.62 & 24.13 & 0.033 \\
\hline Severe(8-11) & 174 & 23.38 & 108.67 & 1.53 & 0.226 \\
\hline
\end{tabular}

\section{DISCUSSION}

Clinical significance of serum amylase, serum glucose and acute pancreatitis following acute organophosphorous compound ingestion has been reported now and then, but there are no large-scale studies with reference to clinical significance of serum amylase, serum glucose and acute pancreatitis.

In our study, in patients with mild OP poisoning the mean initial serum amylase level was $152.67 \pm 73.92$ U. Patients with moderate OP poisoning had a mean initial serum amylase level of $213.38 \pm 69.39 \mathrm{U}$, where as in severe OP poisoning the mean initial serum amylase level was $171.33 \pm 107.22$ U. Our results showed that there was increase in serum amylase level in all patients with OP poisoning but level did not increase in proportion with the severity of POP score.

Study of Singh et $\mathrm{al}^{6}$ showed mild elevation of serum amylase is common in OP poisoning but acute pancreatitis is rare. Serum amylase was elevated $>200$ (S.U) in $37(46.95 \%)$ patients. Only one had acute pancreatitis. Similarly, no patient developed symptomatic acute pancreatitis in our study.

Ahmed Arshia et $\mathrm{al}^{7}$ found hyperamylasemia in $28(31 \%)$ of patients amongst 90 . And pancreatitis was seen in $2(2.2 \%)$ patients. Hyperamylasemia is more frequently seen in organophosphorus poisoning then acute pancreatitis as a complication.

Similar study of Wui-Chiang Lee et $\mathrm{a}^{8}$ also showed 
44(36\%) patients amongst 121 had hyperamylasemia and was not associated with clinical acute pancreatitis. Pancreatic amylase is not a reliable marker of diagnosis of OP induced acute pancreatitis due to its low sensitivity and specicity. Similarly our study showed that serum amylase levels in recovering patients had tendency to decrease to normal value or become normal. All patients had transiently increased serum glucose level.

Kale bhagwat ${ }^{9}$ also found significant increase in serum glucose level $(\mathrm{p}<0.05)$ with severity of OP poisoning.

Similarly Uchil Sudhir et $\mathrm{al}^{10}$ studied the 76 OP poisoned patients. $39(51 \%)$ had consumed organophosphate among them glycosuria alone was observed in 22 cases (56.41\%) and hyperglycemia in 8 cases. Among the 37 carbamate cases, 14 (37.84\%) had glycosuria alone and 5 cases had hyperglycemia in addition. The observed glycosuria and hyperglycemia were transient. Hyperglycemia lasted slightly longer then glycosuria. Their study showed that transient glycosuria with or without hyperglycemia occurred in a significant number of patients with organophosphate and carbamate poisoning.

Serum amylase and glucose levels were increased in all OP poisoning patients in our study which did not corresponds to the severity of OP poisoning. No patient developed acute pancreatitis.

Subash Chandra Joshi et al ${ }^{11}$ study showed the commonest motive of poisoning in both males $(50.80 \%)$ and females $(43.01 \%)$ was suicidal.

a retrospective analysis of poison cases done at $\mathrm{TU}$ Teaching Hospital revealed $6 \%$ of accidental poisoning among 178 study subjects. ${ }^{12}$

In our study, all the patients had consumed for suicidal attempt (100\%) and none of them were accidental. In comparison with deliberate self-harming by poisons, accidental poisonings are far less frequent in other studies as well. . $^{13,14,15}$

\section{CONCLUSION}

The results of this study showed that there was increase in serum amylase level in all patients with OP poisoning but do not corresponds to the severity of POP score. The serum glucose level was increased with the increase in score and was statistically significant in mild and moderately severe OP poisoning but not in severe poisoning. Serum amylase and glucose levels in recovering patients showed a tendency to decrease or became normal during the period of hospital stay. No patient had developed acute pancreatitis, however several study had shown that it is a rare complication of OP poisoning. Therefore the measurement of serum amylase has less value in the absence of clinical acute pancreatitis. Further studies with larger sample size would be ideal to get a more accurate result.

\section{REFERENCES}

1. Jeyaratnam J. Acute pesticide poisoning: A major global health problem. World Health Stat Q.1990;43:139-44.

2. Gupta SK, Joshi MP. Pesticide poisoning cases attending five major hospitals of Nepal. J Nep Med Assoc 2002;41:447-56.

3. Paudyal BP. Poisoning: Pattern and profile of admitted cases in a hospital in central Nepal. J Nep Med Assoc 2005;44:92-96.

4. Vanneste Y, Lison D. Biochemical changes associated with muscle fibre necrosis after experimental organophosphate poisoning. Hum Exp Toxicol.1993;12:365-70.

5. Bhattacharyya K, Phaujdar S, Sarkar. Serum creatine kinase: A probable marker of severity in organophosphorus poisoning. Toxicol Int 2011;18:117-23.

6. Singh S, Bhardwaj U, Verma SK, Bhalla A, Gill K. Hyperamylasemia and acute pancreatitis following anticholinesterase poisoning. Hum ExpToxicol 2007 Jun;26(6):467-71

7. Ahmed A, Begum I, Aquil N, Atif S, Hussain T, Vohra EA. Hyperamylasemia and acute pancreatitis following organophosphate poisoning. Pak J Med Sci 2009;25 (6):957-961.

8. Wui-Chiang Lee, Chen-Chang Yang, Jou-Fang Deng, Ming-Ling Wu, JiinGer, Han-Chieh Lin, Full-Young Chang and Shou-Dong Lee. The Clinical Significance of Hyperamylasemia in Organophosphate Poisoning. J Toxicol Clin Toxicol 1998, Vol. 36, No.7, Pages 673-681

9. Kale Bhagwat .Corelation between glucose level, lipid profile and risk of coronary heart disease associated with organophosphorus pesticide 
poisoning. International Journal of Biological Research, 2 (2) (2014) 78-80

10. Uchil Sudhir, Chandrashekar, Raghavendra Pai, Sunil H S, Medha Y Rao and Punith Kempegowda. glycemic change in acute anticholinesterase insecticide poisoning. The West London Medical Journal 2013 Vol 5 No 1 pp 27-33

11. Subhash Chandra Joshi, Chandra Prakash, Arun Joshi, Godawari Joshi. Profile of Organophosphorus Poisoning At Tertiary Care Hospital in Uttarakhand. J Indian Acad Forensic Med. October-December 2013, Vol. 35, No. 4 ISSN 0971-0973.

12. Prasad PN, Karki P. Poisoning cases at TUTH emergency; a one-year review. J Inst Med 1997; 19: 18-24.

13. M. Eddleston. Patterns and problems of deliberate self-poisoning in the developing world QJM (2000) 93 (11): 715-731.

14. Paudyal BP. Poisoning: Pattern and profile of admitted cases in a hospital in ce 'ntral Nepal. J Nep Med Assoc 2005;44:92-6.

15. Gupta SK, Joshi MP. Pesticide poisoning cases attending five major hospitals of Nepal. J Nep Med Assoc 2002;41:447-56. 